\title{
Automatic Generation Control of Nuclear Heating Reactor Power Plants
}

\author{
Zhe Dong * , Miao Liu, Di Jiang, Xiaojin Huang, Yajun Zhang and Zuoyi Zhang
}

Institute of Nuclear and New Energy Technology, Collaborative Innovation Centre of Advanced Nuclear Energy Technology, Key Laboratory of Advanced Reactor Engineering and Safety of Ministry of Education, Tsinghua University, Beijing 100084, China; liu-m17@mails.tsinghua.edu.cn (M.L.); fyjiangdi@tsinghua.edu.cn (D.J.); huangxj@tsinghua.edu.cn (X.H.); yajun61@tsinghua.edu.cn (Y.Z.); zyzhang@tsinghua.edu.cn (Z.Z.)

* Correspondence: dongzhe@tsinghua.edu.cn; Tel.: +86-10-6278-3764

Received: 12 September 2018; Accepted: 12 October 2018; Published: 16 October 2018

check for updates

\begin{abstract}
A nuclear heating reactor (NHR) is a typical integral pressurized water reactor (iPWR) with advanced design features such as an integral primary circuit, self-pressurization, full-power-range natural circulation, and hydraulic control rods. Through adjusting its electric power output according to the variation of demand, NHR power plants can be adopted to stablize the fluctuation of grid frequency caused by the intermittent nature of renewable generation, which is useful for deepening the penetration of renewables. The flexibility of an NHR power plant relies on the automatic generation control (AGC) function of the plant coordination control system, whose central is the AGC law. In this paper, the plant control system with AGC function is designed for NHR plants, where the AGC is realized based on the stabilizers of grid frequency and main steam pressure. Then, the AGC problem is transferred to the disturbance attenuation problem of a second-order dynamic system, and an active disturbance attenuation control (ADRC), which is just the addition of a feedback control given by a proportional-integral (PI) law and a feedforward control driven by a disturbance observer (DO), is then proposed. Finally, this ADRC is applied to realize the AGC function for NHR-200II reactor power plant, and numerical simulation results show the implementation feasibility and satisfactory performance.
\end{abstract}

Keywords: small modular reactor (SMR); nuclear heating reactor (NHR); automatic generation control (AGC); active disturbance rejection control (ADRC)

\section{Introduction}

Due to their zero marginal cost of electricity production, renewable energy sources such as wind and solar are regarded as important contributors to the world electric power provision. However, renewable generation not only heavily depends on climatic conditions but also requires a very large land footprint. With comparison to renewables, nuclear power plants (NPPs) can provide consistent electricity while requiring much less land [1]. Moreover, to balance the power supply and demand in the context of deep renewable penetration, it is necessary to provide enough backup flexibility, which can be provided on a large scale by burning fossil fuels or nuclear fission reactions. Since nuclear fission and renewables are both clean energy resources, it is meaningful to interconnect them for building carbon-free energy systems, i.e., nuclear hybrid energy systems (NHESs). One of the key techniques in developing NHESs is the flexibility of NPPs, which refers to the capability of adjusting the plant electric power output according to demand, and can further deepen the penetration of renewables through reducing their curtailment. It has been shown that the flexibility of NPPs is realizable if the limitations in axial power offset, fuel integrity, fission product poisoning, and temperature variation are all well satisfied [2], and is a crucial factor in maximizing the profit of producers [3,4]. A case 
study based on utility data from the Southwest USA in [5] shows that the flexibility of NPPs can not only increase the revenue of NPP owners but also lower the operational cost of the grid. It is even pointed out through analysis in [6] that adopting small modular nuclear reactors (SMRs) to balance the renewables is the only existing technology that can provide reliable, carbon-free electricity in a scalable manner. Small modular reactors (SMRs) are defined as those fission reactors whose electrical power is less than $300 \mathrm{MW}_{\mathrm{e}}$, and have already been seen as an important trend in the nuclear energy industry [7-10]. SMRs with integral primary circuits and light-water as primary coolant are called integral pressurized water reactors (iPWRs). The IRIS, NuScale, and mPower designed by the USA and the SMART designed by Korea are all typical iPWR designs with advanced features such as natural circulation, self-pressurization, hydraulic control rod, and passive decay heat removal, which prevents the reactors from hazards such as core-melting, radiological release, and LOCA (Loss of Coolant Accident). Moreover, iPWRs can offer simpler, safer, and standardized modular design by being factory built, requiring smaller initial capital investment and having a shorter construction period $[7,8]$. Due to their improved nuclear safety level, iPWRs are more feasible than large-scale PWRs.

A nuclear heating reactor (NHR) is a typical iPWR with inherent safety features such as integral primary circuit, full-power-range natural circulation, self-pressurization, and built-in hydraulic control rods [11-18]. Due to these features, no off-site emergency actions such as evacuation, sheltering, and decontamination are required in the case of all credible accidents. The study of NHR technology started in China in the early 1980s, and the first NHR, i.e., the $5 \mathrm{MW}_{\text {th }}$ test reactor $\left.{ }^{*} \mathrm{NHR}-5\right)$, began to be built at the Institute of Nuclear and New Energy Technology (INET) of Tsinghua University in March 1986, and has operated at full power since December 1989 [11-13]. Based on NHR-5, the design of a $200 \mathrm{MW}_{\text {th }}$ nuclear heating reactor (NHR-200) was accomplished in the middle of the 1990s; it is used for electricity generation, district heating, and seawater desalination [14-17]. On the basis of the NHR-200 design, and by improving the pressure of the primary coolant and live steam for higher efficiency, a nuclear heating reactor NHR200-II with a rated thermal power of $200 \mathrm{MW}_{\text {th }}$ was developed by INET very recently [18]. Although the power rating of NHR-200II is relatively low, due to its inherent safety features it can be adopted to balance renewables by adjusting its electric power output, which relies on the automatic generation control (AGC) of the NHR-200II plant.

The past and current study of the control of nuclear plants mainly focuses on the power-level control of nuclear reactors, and a series of advanced control methods have been developed such as sliding mode control (SMC), model predictive control (MPC), and physics-based control (PBC) approaches [19]. However, there are still very limited results on AGC of nuclear plants. In this paper, a control system scheme with AGC function is first designed for the NHR-200II power plant. Then, the problems stabilizing the main steam pressure and grid frequency are transferred to the disturbance attenuation problem of a second-order dynamical system, and an active disrurbance rejection control (ADRC) is proposed, composed of a proportional-integral feedback term and a feedforward term given by a disturbance observer (DO). Finally, this ADRC is applied to realize the AGC function for a NHR-200II power plant, and numerical simulation results in the cases of power stepping and maneuvering show the feasibility and satisfactory performance.

\section{General Description of NHR-200II Power Plant}

The structure of NHR-200II is illustrated in Figure 1, from which it can be seen that the reactor system and primary circuit (PC), including the riser, downcomer, and 14 primary heat exchangers (PHEs), are arranged into the reactor pressure vessel (RPV). The core is located at the bottom of RPV, which is composed of fuel assemblies with fuel boxes and cruciform control rods. The PHEs are arranged in the annular space between the riser and RPV. The natural circulation of PC, which can sufficiently cool down the reactor core in the full power range, is driven by the density difference between the coolant inside the core and PHEs, and is hydraulically enhanced by the riser. Futhermore, the schematic diagram of the NHR-200II power plant is shown in Figure 2. 
The heat generated by a nuclear fission reaction is transferred from the primary circuit (PC) to the two intermediate circuits (ICs) via the PHEs, and is successivefully transferred to the secondary side of UTSGs so as to turn the supercooled feedwater into saturated steam. Then the main steam flow formed by the combination of the live steam flows from two UTSGs is guided to the high-pressure (HP) cylinder of the turbine so as to drive the turbine/generator set for producing electrical power. A comparison of the main design parameters of the NHR-200II plant and those of the NHR-200 plant is given in Table 1. It can be seen from Table 1 that the ICs operate at a pressure that is a little higher than the pressure of PC, which can effectively suppress the leakage of radioactive fission products.

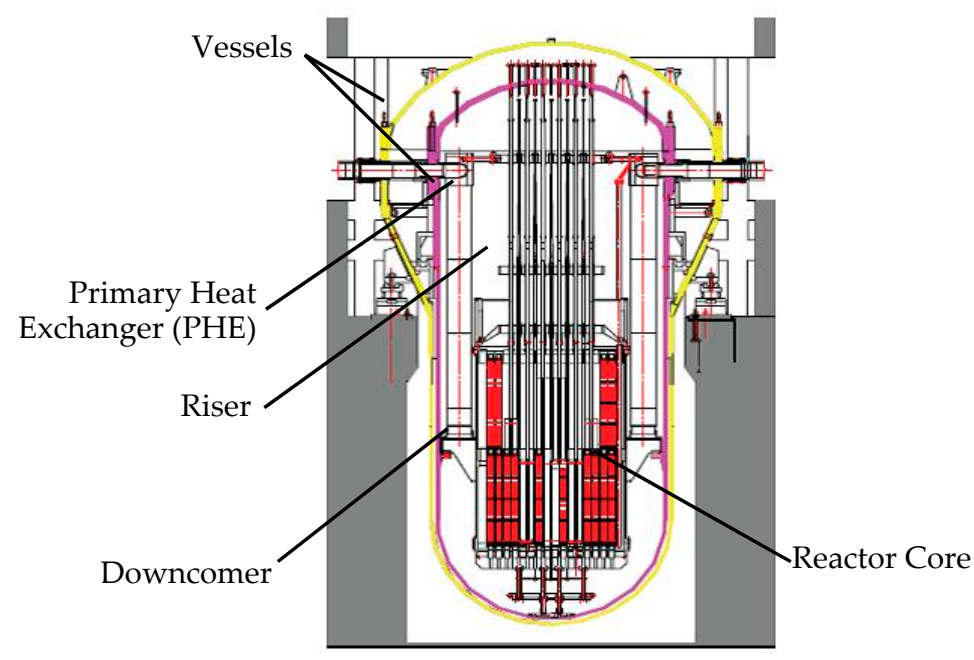

Figure 1. Schematic structure of nuclear heating reactor (NHR).

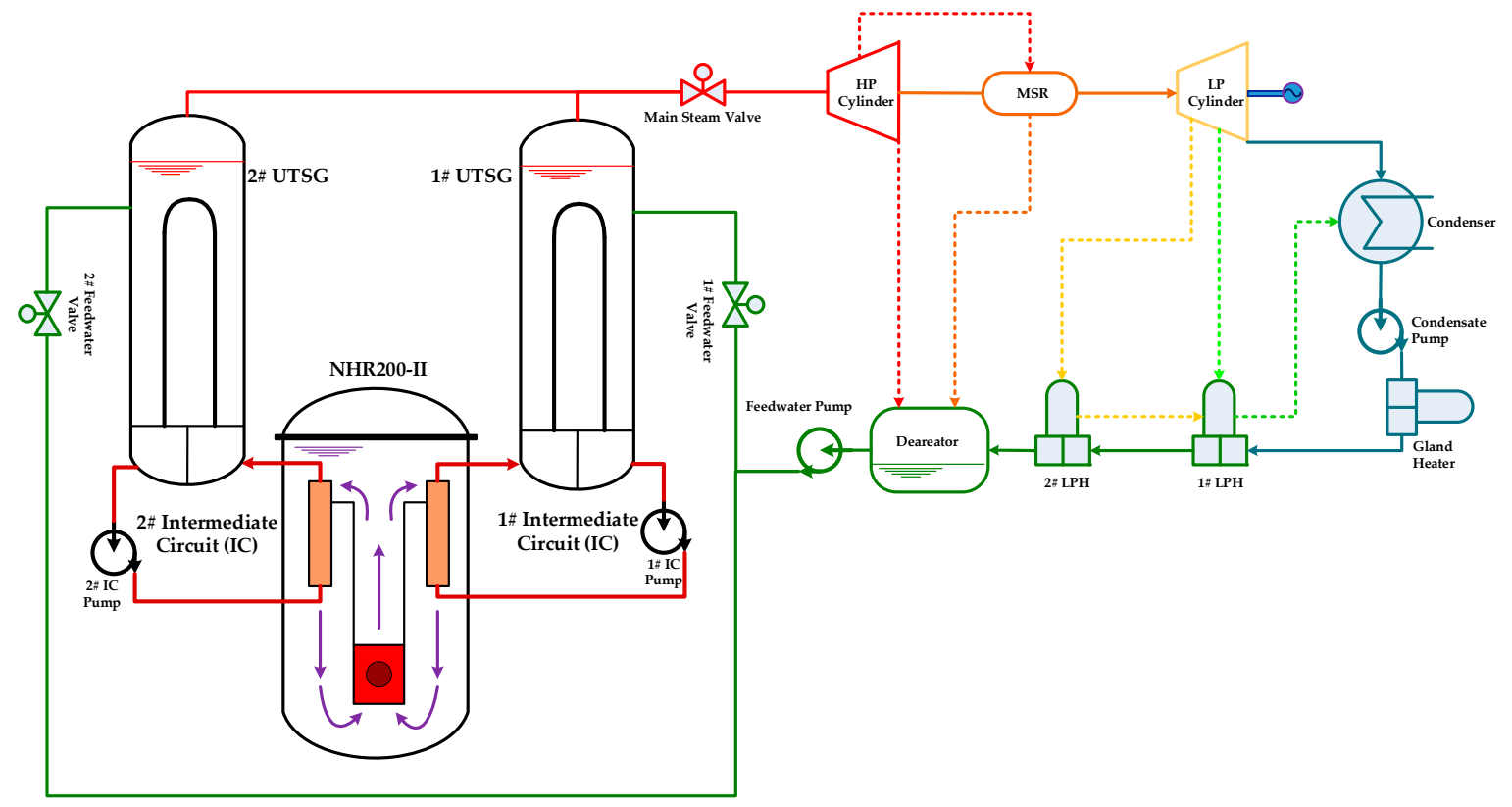

Figure 2. Shematic process diagram of the nuclear heating reactor (NHR)-based power plant. 
Table 1. Main design parameters of NHR-200 and NHR-200II.

\begin{tabular}{llll}
\hline Parameter & Unit & NHR-200 & NHR-200II \\
\hline Thermal Power & $\mathrm{MW}$ th & 200 & 200 \\
Coolant/Moderator & & Light Water & Light Water \\
Circulation Type & & Natural Circulation & Natual Circulation \\
Primary Circuit Pressure & $\mathrm{MPa}$ & 2.5 & 8 \\
Core Inlet/Outlet Temperature & ${ }^{\circ} \mathrm{C}$ & $145 / 210$ & $232 / 280$ \\
Intermediate Circuit Pressure & $\mathrm{MPa}$ & 3.0 & 8.8 \\
IC Cold/Hot Leg Temperature & ${ }^{\circ} \mathrm{C}$ & $95 / 145$ & $203 / 248$ \\
Live Steam Pressure & $\mathrm{Mpa}$ & 0.25 & 1.6 \\
Live Steam Temperature & ${ }^{\circ} \mathrm{C}$ & 127.4 & 201.4 \\
\hline
\end{tabular}

\section{Plant Control Scheme with AGC Function}

To achieve flexible operation of NHR and deepen the penetration of IRE, it is necessary to realize automatic generation control. The designed hierarchy control scheme of NHR power plants with automatic generation function is shown in Figure 3, from which it can be seen that the entire closed loop is divided into the levels of process, equipment, system controlm and coordination. The process level is composed of the physical and thermal-hydraulic processes including the NHR, ICs, UTSGs, and turbine-generator set. The equipment level is the collection of sensors and actuators related to plant control such as the control rods, pumps, regulating valves, and nuclear and thermal-hydraulic intruments. The system control level is constituted of those control systems for regulating the neutron flux, reactor core outlet temperature, IC flowrate, UTSG water level, and grid frequency according to their measurements and setpoints. The coordination level is proposed to keep the balance between thermal power generated by the NHR and electric power delivered to the grid, which is realized by the main steam pressure controller.

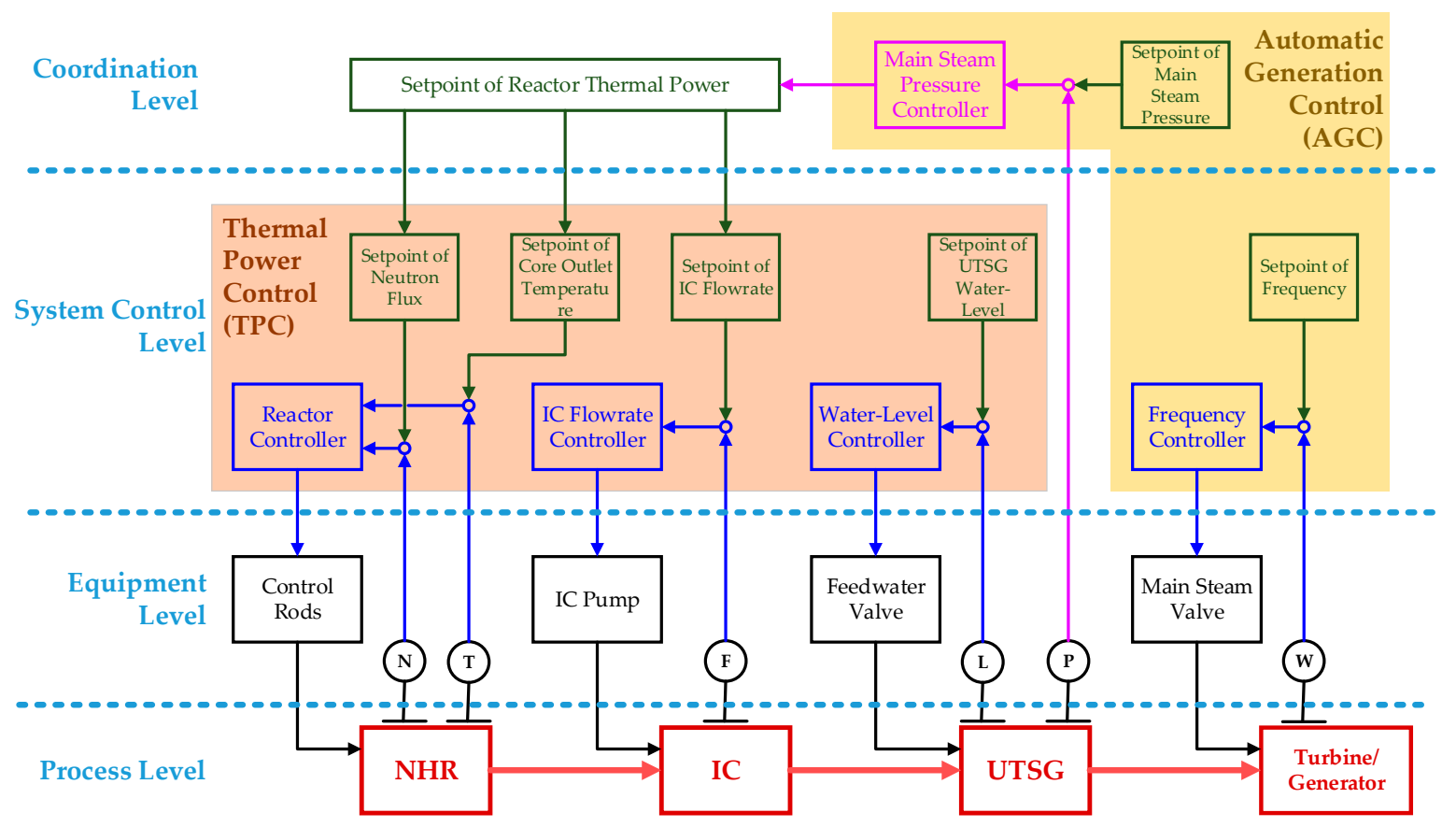

Figure 3. Control scheme diagram of nuclear heating reactor (NHR) power plant.

The reactor controller, IC flowrate controller, and UTSG water-level controller form the thermal power control (TPC) system. The reactor controller regulates the neutron flux and reactor core oulet temperature through adjusting the control rod speed so as to suppress mismatches between the measurements and the setpoints of neutron flux and core outlet temperature.The IC flowrate controller 
realizes the tracking of IC flowrate with its setpoint for strengthening the heat transfer between PC and ICs. The water-level controller is used to stabilize the UTSG water level for generating high-quality saturated steam. The study in the past was focused on the design of TPC systems, and there have been some promising results in the TPC of nuclear steam supply system (NSSS). A series of promising TPC methods have been proposed such as the sliding mode control (SMC), model predictive control (MPC), and the physics-based nonlinear control method.

The automatic generation control (AGC) system is constituted by the frequency controller and main steam pressure controller. The frequency controller, which is used to balance the electrical supply from the plant and demand from the grid, regulates the live steam flowrate through adjusting the opening of the main steam valve so as to stabilize the grid frequency. Since the live steam is saturated, the steam pressure and temperature are one-to-one. The stabilization of frequency results in the variation of a live steam flowrate that further leads to the variation of live steam pressure while causing a variation in steam temperature. Actually, the steam pressure is the key process variable denoting the balance between thermal power provision from NSSS and consumption in the turbine-generator set. The main steam pressure controller in the coordination level shown in Figure 3, which is adopted to realize thermal power balance, is designed to stabilize the main steam pressure through adjusting the setpoint of the reactor's themal power. The thermal power setpoint determines the setpoints of neutron flux, reactor core outlet temperature, and IC flowrates.

In the past, nuclear fission energy was regarded as a clean baseload energy source that can be substituted for fossil fuels in large amounts. Commercial NPPs mostly operate in the mode of the turbine following reactor, i.e., the live steam pressure is stabilized by adjusting the opening of the main steam valve. There are very limited results from studying AGC methods for NPPs. For improving the penetration level of renewables so as to effectively avoid uneconomical curtailment, it is important for NPPs to operate in the load following mode to provide flexibility. Related to this is the necessity of realizing the AGC function of NHR plants. As discussed above, the central AGC system of NHR plants controls grid frequency and steam pressure.

\section{Automatic Genration Control Laws}

The automatic generatioin control laws refer to the frequency controller as well as the main steam pressure controller shown in Figure 3. In this section, a disturbance attenuation control problem is formulated and an active disturbance rejection control law is proposed, which is suitable for frequency and pressure control. It is also shown that the control law can be generalized for AGC design of PWR plants.

\subsection{State-Space Modeling for Control Design}

1. State-Space Model for Steam Pressure Stabilization

The energy balance for the secondary side of UTSG can be described by

$$
\frac{\mathrm{d}}{\mathrm{d} t}\left(\rho_{\mathrm{s}} h_{\mathrm{s}} V_{\mathrm{s}}\right)=Q_{\mathrm{in}}+G_{\mathrm{fw}} h_{\mathrm{fw}}-G_{\mathrm{st}} h_{\mathrm{st}}
$$

where $h_{\mathrm{st}}$ and $h_{\mathrm{fw}}$ are the specific enthalpies of live steam and feedwater of UTSG, respectively; $G_{\mathrm{st}}$ and $G_{\mathrm{fw}}$ are the mass flowrates of live steam and feedwater, respectively; $Q_{\text {in }}$ is the heat transferred from the primary to the secondary sides of UTSG; $\rho_{\mathrm{s}}$ and $h_{\mathrm{s}}$ are the average density and specific enthalpy of the UTSG secondary coolant respectively; and constant $V_{\mathrm{s}}$ is the secondary-side volume of UTSG.

Suppose average density $\rho_{\mathrm{s}}$ and specific enthalpy $h_{\mathrm{s}}$ satisfies

$$
\rho_{\mathrm{s}} h_{\mathrm{s}}=\frac{\rho_{\mathrm{st}} h_{\mathrm{st}}+\rho_{\mathrm{fw}} h_{\mathrm{fw}}}{2}
$$


where $\rho_{\mathrm{fw}}$ and $h_{\mathrm{fw}}$ are the density and enthalpy of UTSG feedwater, respectively. Moreover, it is assumed that both $\rho_{\mathrm{fw}}$ and $h_{\mathrm{fw}}$ are constant.

By substituting Equation (2) into Equation (1) and considering the saturation nature of live steam, we see that

$$
\frac{V_{\mathrm{s}}}{2}\left(\frac{\partial \rho_{\mathrm{st}} h_{\mathrm{st}}}{\partial P_{\mathrm{st}}}\right) \dot{P}_{\mathrm{st}}=Q_{\mathrm{in}}+G_{\mathrm{fw}} h_{\mathrm{fw}}-G_{\mathrm{st}} h_{\mathrm{st}}
$$

where $P_{\text {st }}$ is the live steam pressure. At steady state, steam pressure $P_{\text {st }}$ equals its steady value $P_{\text {st0 }}$, and

$$
Q_{\mathrm{in} 0}+G_{\mathrm{fw} 0} h_{\mathrm{fw}}-G_{\mathrm{st} 0} h_{\mathrm{st} 0}=0,
$$

where $Q_{\mathrm{in} 0}, G_{\mathrm{fw} 0}, G_{\mathrm{st} 0}$ and $h_{\mathrm{st} 0}$ are all steady values of process variables $Q_{\mathrm{in}}, G_{\mathrm{fw}}, G_{\mathrm{st}}$ and $h_{\mathrm{st}}$, respectively.

Subtracting Equation (4) from Equation (3), we get

$$
\frac{V_{\mathrm{s}}}{2}\left(\left.\frac{\partial \rho_{\mathrm{st}} h_{\mathrm{st}}}{\partial P_{\mathrm{st}}}\right|_{P_{\mathrm{st} 0}}\right) \Delta \dot{P}_{\mathrm{st}}=-G_{\mathrm{st}}\left(\left.\frac{\partial h_{\mathrm{st}}}{\partial P_{\mathrm{st}}}\right|_{P_{\mathrm{st} 0}}\right) \Delta P_{\mathrm{st}}+\left(\Delta Q_{\mathrm{in}}+\Delta G_{\mathrm{fw}} h_{\mathrm{fw}}-\Delta G_{\mathrm{st}} h_{\mathrm{st} 0}\right),
$$

where the first term reflects dissipation and the second term reflect the inbalance of thermal power input and output, $\Delta P_{\mathrm{st}}=P_{\mathrm{st}}-P_{\mathrm{st} 0}, \Delta Q_{\mathrm{in}}=Q_{\mathrm{in}}-Q_{\mathrm{in} 0}, \Delta G_{\mathrm{fw}}=G_{\mathrm{fw}}-G_{\mathrm{fw} 0}$ and $\Delta G_{\mathrm{st}}=G_{\mathrm{st}}-G_{\mathrm{st} 0}$.

Moreover, $\Delta Q_{\text {in }}$ can be further expressed as

$$
\Delta Q_{\text {in }}=P_{\mathrm{thr}} \Delta p_{\mathrm{r}}+d_{\mathrm{th}}
$$

where $P_{\text {thr }}$ is the rated thermal power, $\Delta p_{\mathrm{r}}$ is the setpoint variation of normalized thermal power, and $d_{\text {th }}$ is the mismatch between $\Delta Q_{\mathrm{in}}$ and its expected value given by $P_{\mathrm{thr}} \Delta p_{\mathrm{r}}$. Substitute Equation (6) into Equation (5) and we get

$$
\frac{V_{\mathrm{s}}}{2}\left(\left.\frac{\partial \rho_{\mathrm{st}} h_{\mathrm{st}}}{\partial P_{\mathrm{st}}}\right|_{P_{\mathrm{st} 0}}\right) \Delta \dot{P}_{\mathrm{st}}=-G_{\mathrm{st}}\left(\left.\frac{\partial h_{\mathrm{st}}}{\partial P_{\mathrm{st}}}\right|_{P_{\mathrm{st} 0}}\right) \Delta P_{\mathrm{st}}+P_{\mathrm{thr}} \Delta p_{\mathrm{r}}+\left(d_{\mathrm{th}}+\Delta G_{\mathrm{fw}} h_{\mathrm{fw}}-\Delta G_{\mathrm{st}} h_{\mathrm{st} 0}\right) .
$$

Define the state-vector as

$$
x=\left[\begin{array}{ll}
x_{1} & x_{2}
\end{array}\right]^{\mathrm{T}}=\left[\begin{array}{ll}
\int_{0}^{t} \Delta P_{s t}(\tau) \mathrm{d} \tau & \Delta P_{\mathrm{st}}
\end{array}\right]^{\mathrm{T}}
$$

and then the state-space model for control design can be written as

$$
E \dot{x}=A(x) x+b u+d,
$$

where $u$ is the control input to be designed for stabilizing $x, d$ is the disturbance to be attenuated.

$$
\begin{aligned}
\boldsymbol{E} & =\left[\begin{array}{ll}
1 & 0 \\
0 & E
\end{array}\right] \\
\boldsymbol{A}(\boldsymbol{x}) & =\left[\begin{array}{cc}
0 & 1 \\
0 & -A(\boldsymbol{x})
\end{array}\right] \\
\boldsymbol{b} & =\left[\begin{array}{ll}
0 & b
\end{array}\right]^{\mathrm{T}} \\
\boldsymbol{d} & =\left[\begin{array}{ll}
0 & d
\end{array}\right]^{\mathrm{T}}
\end{aligned}
$$




$$
\begin{gathered}
E=\frac{V_{\mathrm{s}}}{2}\left(\left.\frac{\partial \rho_{\mathrm{st}} h_{\mathrm{st}}}{\partial P_{\mathrm{st}}}\right|_{P_{\mathrm{st} 0}}\right) \\
A(x)=G_{\mathrm{st}}\left(\left.\frac{\partial h_{\mathrm{st}}}{\partial P_{\mathrm{st}}}\right|_{P_{\mathrm{st} 0}}\right) \\
b=P_{\mathrm{thr}} \\
d=d_{\mathrm{th}}+\Delta G_{\mathrm{fw}} h_{\mathrm{fw}}-\Delta G_{\mathrm{st}} h_{\mathrm{st} 0 .}
\end{gathered}
$$

2. State-Space Model for Frequency Stabilization

Grid frequency is given by the rotation-rate of synchronous generators connected with the grid. The swing equation of a synchronous generator can be expressed as

$$
\left\{\begin{array}{l}
\dot{\delta}=(\omega-1) \omega_{0}, \\
\dot{\omega}=\frac{P_{\mathrm{m}}}{\omega H}-T_{\mathrm{e}}
\end{array}\right.
$$

where $\delta$ is the rotor angle with respect to the synchronously rotating reference frame in electrical radians, $\omega$ is the grid frequency, $H$ is the mechanical inertia of rotor, $P_{\mathrm{m}}$ is the input mechanical power from the turbine, $T_{\mathrm{e}}$ the electromagnetic torque.

For a multimachine power grid interconnecting $n(n \geq 2)$ synchronous generators,

$$
T_{\mathrm{e}}=G E_{\mathbf{q}}^{\prime 2}+E_{\mathrm{q}}^{\prime} \sum_{k=1}^{n-1} \omega_{k} E_{\mathbf{q}, k}^{\prime}\left(G_{k} \cos \delta_{k}+B_{k} \sin \delta_{k}\right),
$$

where $G$ and $E^{\prime}$ are the self-conductance and transient voltage of the local generator, respectively; $\delta_{k}$ is the phase anlge of the $k$ th $(k=1, \cdots, n-1)$ remote generator relative to the local generator; and $w_{k}, E_{\mathrm{q}, k}^{\prime}, G_{k}$, and $B_{k}$ are the rotation rate, transient voltage, conductance, and susceptibility of the $k$ th remote generator, respectively.

Define the steady values of $\delta, \omega, P_{\mathrm{m}}$, and $T_{\mathrm{e}}$ as $\delta_{0}, \omega_{0}, P_{\mathrm{m} 0}$, and $T_{\mathrm{e} 0}$, respectively, and it can be seen from Equation (18) that $\omega_{0}=1$ and $P_{\mathrm{m} 0}=T_{\mathrm{e} 0}$. Based on defining $\Delta \delta=\delta-\delta_{0}, \Delta \omega=\omega-\omega_{0}, \Delta P_{\mathrm{m}}$ $=P_{\mathrm{m}}-P_{\mathrm{m} 0}$, and $\Delta T_{\mathrm{e}}=T_{\mathrm{e}}-T_{\mathrm{e} 0}$, it can then be derived that

$$
\left\{\begin{array}{l}
\Delta \dot{\delta}=\Delta \omega \\
H \Delta \dot{\omega}=-\frac{P_{\mathrm{m}}}{\omega} \Delta \omega+\Delta P_{\mathrm{m}}-\Delta T_{\mathrm{e}}
\end{array}\right.
$$

Since $\Delta P_{\mathrm{m}}$ can be decomposed as

$$
\Delta P_{\mathrm{m}}=\frac{\Delta G_{\mathrm{st}}}{G_{\mathrm{st} 0}}+d_{\mathrm{m}}
$$

where $G_{\text {st } 0}$ is the steam flowrate at full power, $d_{\mathrm{m}}$ is the mismatch between the other two terms, Equation (20) can be rewritten as

$$
\left\{\begin{array}{l}
\Delta \dot{\delta}=\Delta \omega, \\
H \Delta \dot{\omega}=-\frac{P_{\mathrm{m}}}{\omega} \Delta \omega+h_{\mathrm{st} 0} \Delta G_{\mathrm{st}}+d_{\mathrm{m}}-\Delta T_{\mathrm{e}} .
\end{array}\right.
$$

Define the state-vector for frequency stabilization as

$$
\boldsymbol{x}=\left[\begin{array}{ll}
x_{1} & x_{2}
\end{array}\right]^{\mathrm{T}}=\left[\begin{array}{ll}
\Delta \delta & \Delta \omega
\end{array}\right]^{\mathrm{T}} .
$$


Equation (22) can be further expressed as the state-space model defined by Equations (9)-(13), with scalars $E, A$, and $d$, as well as constant $b$, given by

$$
\begin{gathered}
u=\Delta G_{\mathrm{st}} \\
E=H \\
A(x)=\frac{P_{\mathrm{m}}}{\omega}=\frac{P_{\mathrm{m}}}{1+x_{2}} \\
b=G_{\mathrm{st} 0}^{-1} \\
d=d_{\mathrm{m}}-\Delta T_{\mathrm{e}},
\end{gathered}
$$

respectively. Here, control input $u=\Delta G_{\text {st }}$ should be designed to stabilize frequency error $\Delta \omega$.

\subsection{Theorectical Control Problem Formulation}

From the above state-space modeling, the state-space models for designing stabilizers of steam pressure and grid frequency take the same form as the system given by Equations (9)-(13), i.e.,

$$
\left\{\begin{array}{l}
\boldsymbol{E} \dot{\boldsymbol{x}}=\boldsymbol{A}(\boldsymbol{x}) \boldsymbol{x}+\boldsymbol{b} u+\boldsymbol{d}, \\
\boldsymbol{E}=\left[\begin{array}{ll}
1 & 0 \\
0 & E
\end{array}\right], \\
\boldsymbol{A}(\boldsymbol{x})=\left[\begin{array}{ll}
0 & 1 \\
0 & -A(\boldsymbol{x})
\end{array}\right], \\
\boldsymbol{b}=\left[\begin{array}{ll}
0 & b
\end{array}\right]^{\mathrm{T}}, \\
\boldsymbol{d}=\left[\begin{array}{ll}
0 & d
\end{array}\right]^{\mathrm{T}}, \\
A(\boldsymbol{x})>0, E>0 .
\end{array}\right.
$$

For stabilizing steam pressure and grid frequency, it is meaningful to solve the disturbance control problem summarized as follows:

Problem 1. Consider dynamical system (29), where both state variables $x_{1}$ and $x_{2}$ can be obtained through measurement. Futher, suppose that the differentiation of disturbance d

$$
\dot{d}=D
$$

is norm-bounded, i.e.,

$$
|D| \leq M_{\mathrm{d}}
$$

where $M_{\mathrm{d}}$ is a bounded positive constant. How can we design the control input $u$ so that the closed-loop system is globally bounded and stable?

\subsection{Active Disturbance Rejection Control Law}

The following theorem gives an active disturbance rejection control law for dynamic system (29) with disturbance $d$ satisfying inequality (31).

Theorem 1. Consider system (29), whose state variables can be given by measurement. Suppose that disturbance $d$ satisfies inequality (31) with $M_{\mathrm{d}}$ being bounded. Then, active disturbance rejection control (ADRC)

$$
u=-\frac{E}{b}\left(k_{1} x_{1}+k_{2} x_{2}\right)-\frac{\hat{d}}{b}
$$


where $k_{i}>0(i=1,2)$ is the feedback gains, and $\hat{d}$ is the estimation of $d$ given by disturbance observer (DO)

$$
\left\{\begin{array}{l}
\dot{\hat{x}}_{2}=-\frac{A(x)}{E} \hat{x}_{2}+\frac{b}{E} u+\frac{\hat{d}}{E}-\frac{\kappa_{1}}{\varepsilon} e_{2}, \\
\hat{d}=-\frac{E \kappa_{2}}{\varepsilon^{2}} e_{2},
\end{array}\right.
$$

with $\kappa_{i}>0(i=1,2)$ is the observer gains, positive constant $\varepsilon \in(0,1)$, and

$$
e_{2}=\hat{x}_{2}-x_{2}
$$

ADRC (32) guarantees globally bounded stability for the closed loop formed by Equations (29), (32), and (33), if polynominal

$$
G(s)=s^{2}+\alpha_{1} s+\alpha_{2}
$$

where $\alpha_{i}=k_{i}$ or $\alpha_{i}=\kappa_{i}(i=1,2)$ is Hurwitz, i.e., the roots of equation $G(s)=0$ have negative real parts.

Proof of Theorem 1. First, the convergence of DO (33) is analyzed. Define the estimation error of total disturbance $d$ as

$$
e_{\mathrm{d}}=\hat{d}-d
$$

Then, from Equations (29), (30), and (33), the observation errors $e_{2}$ and $e_{\mathrm{d}}$ satisfy the dynamical equation

$$
\left\{\begin{array}{l}
\dot{e}_{2}=-\frac{1}{E}\left[\frac{\kappa_{1}}{\varepsilon}+A(x)\right] e_{2}+\frac{e_{\mathrm{d}}}{E}, \\
\dot{e}_{\mathrm{d}}=-\frac{E \kappa_{2}}{\varepsilon^{2}} e_{2}+D .
\end{array}\right.
$$

Based on coordination transformation

$$
\boldsymbol{z}=\left[\begin{array}{ll}
z_{1} & z_{2}
\end{array}\right]^{\mathrm{T}}=\left[\begin{array}{ll}
e_{2} & \frac{\varepsilon e_{\mathrm{d}}}{E}
\end{array}\right]^{\mathrm{T}}
$$

and scale transformation

$$
\tau=\varepsilon^{-1} t
$$

The estimation error dynamics in Equation (37) can be rewritten as

$$
\frac{\mathrm{d} z}{\mathrm{~d} \tau}=\left(A_{\mathrm{o}}-R_{\mathrm{o}}\right) z+\varepsilon^{2} D
$$

where

$$
\begin{gathered}
\boldsymbol{A}_{\mathrm{O}}=\left[\begin{array}{ll}
-\kappa_{1} & 1 \\
-\kappa_{2} & 0
\end{array}\right] \\
\boldsymbol{R}_{\mathrm{O}}=\operatorname{diag}\left(\left[\begin{array}{ll}
0 & A(\boldsymbol{x})
\end{array}\right]\right) \\
\boldsymbol{D}=\left[\begin{array}{ll}
0 & D E^{-1}
\end{array}\right]^{\mathrm{T}} .
\end{gathered}
$$

Since constant $\varepsilon$ is strictly positive, the stability of estimation error dynamic Equation (37) is equivalent to system (40). Moreover, from condition (35), it can be seen that matrix $A_{\mathrm{o}}$ is Hurwitz, which further leads to the fact that for an arbitrarily given diagonal positive-definite matrix $Q_{\mathrm{o}}=\operatorname{diag}\left(\left[q_{\mathrm{o} 1}, q_{\mathrm{o} 2}\right]\right)\left(q_{\mathrm{o} i}>0, i=1,2\right)$, there must be a symmetric positive-definite matrix $\boldsymbol{P}_{\mathrm{o}}$ so that

$$
A_{\mathrm{o}}^{\mathrm{T}} \boldsymbol{P}_{\mathrm{o}}+\boldsymbol{P}_{\mathrm{o}} A_{\mathrm{o}}=-Q_{\mathrm{o}}
$$


Choose the Lyapunov function for system (40) as follows:

$$
V_{\mathrm{o}}(z)=\frac{1}{2} z^{\mathrm{T}} \boldsymbol{P}_{\mathrm{o}} z,
$$

and differentiate function $V_{\mathrm{o}}$ along the trajectory of system (40),

$$
\begin{aligned}
\frac{\mathrm{d} V_{\mathrm{o}}(z)}{\mathrm{d} \tau} & =\frac{1}{2} \boldsymbol{z}^{\mathrm{T}}\left[\boldsymbol{A}_{\mathrm{o}}^{\mathrm{T}} \boldsymbol{P}_{\mathrm{o}}+\boldsymbol{P}_{\mathrm{o}} \boldsymbol{A}_{\mathrm{o}}-\left(\boldsymbol{P}_{\mathrm{o}} \boldsymbol{R}_{\mathrm{o}}+\boldsymbol{R}_{\mathrm{o}} \boldsymbol{P}_{0}\right)\right] \boldsymbol{z}+\varepsilon^{2} \boldsymbol{z}^{\mathrm{T}} \boldsymbol{P}_{\mathrm{o}} \boldsymbol{D} \\
& =-\frac{1}{2} \boldsymbol{z}^{\mathrm{T}} \boldsymbol{Q}_{\mathrm{o}} \boldsymbol{z}-\frac{1}{2} \bar{z}^{\mathrm{T}} \overline{\boldsymbol{R}}_{\mathrm{o}} \overline{\boldsymbol{z}}+\boldsymbol{\varepsilon}^{2} \boldsymbol{z}^{\mathrm{T}} \boldsymbol{D} \\
& \leq-\frac{1}{2} \overline{\boldsymbol{z}}^{\mathrm{T}} \overline{\boldsymbol{R}}_{\mathrm{o}} \overline{\boldsymbol{z}}-\frac{1}{4} \boldsymbol{z}^{\mathrm{T}} \boldsymbol{Q}_{\mathrm{o}} \boldsymbol{z}+\frac{\varepsilon^{4}}{q_{\mathrm{o} 2}}\left[\frac{D}{E} \lambda_{\max }\left(\boldsymbol{P}_{\mathrm{o}}\right)\right]^{2}
\end{aligned}
$$

where $\lambda_{\max }(\cdot)$ gives the maximal eigenvalue of a matrix,

$$
\bar{z}=P_{\mathrm{o}}^{\frac{1}{2}} z
$$

and matrix

$$
\overline{\boldsymbol{R}}_{\mathrm{O}}=\boldsymbol{P}_{\mathrm{O}}^{\frac{1}{2}} \boldsymbol{R}_{\mathrm{O}} \boldsymbol{P}_{\mathrm{O}}^{-\frac{1}{2}}+\boldsymbol{P}_{\mathrm{O}}^{-\frac{1}{2}} \boldsymbol{R}_{\mathrm{O}} \boldsymbol{P}_{\mathrm{O}}^{\frac{1}{2}}
$$

is semipositive-definite symmetric. From inequality (46), state-vector $z$ converges asymptotically to a bounded set around the origin, which means that DO (33) provides a globally bounded estimation for total disturbance $d$. The constant $\varepsilon$ is smaller and scalars $q_{\mathrm{o} i}(i=1,2)$ are larger; the bounded set is tighter, where larger $q_{\mathrm{o} i}(i=1,2)$ are guaranteed by more negative real parts for the roots of equation $s^{2}+\kappa_{1} s+\kappa_{2}=0$.

Second, the closed-loop stability formed by system (29), ADRC (32), and DO (33) is analyzed. From Equations (29) and (32), the closed-loop dynamics can be written as

$$
\dot{x}=\left(A_{\mathrm{c}}-R_{\mathrm{c}}\right) x+E_{\mathrm{d}},
$$

where

$$
\begin{gathered}
A_{\mathrm{c}}=\left[\begin{array}{cc}
0 & 1 \\
-k_{1} & -k_{2}
\end{array}\right] \\
\boldsymbol{R}_{\mathrm{c}}=\operatorname{diag}\left(\left[\begin{array}{ll}
0 & \frac{A(x)}{E}
\end{array}\right]\right) \\
\boldsymbol{E}_{\mathrm{d}}=\left[\begin{array}{ll}
0 & e_{\mathrm{d}}
\end{array}\right]^{\mathrm{T}} .
\end{gathered}
$$

From condition (35), it can be seen that matrix $A_{\mathrm{c}}$ is Hurwitz, which means that for an arbitrarily given diagonal matrix $Q_{\mathrm{c}}=\operatorname{diag}\left(\left[q_{\mathrm{c} 1}, q_{\mathrm{c} 2}\right]\right)\left(q_{\mathrm{c} i}>0, i=1,2\right)$, there exists a symmetric positive-definite matrix $\boldsymbol{P}_{\mathrm{c}}$ so that

$$
A_{\mathrm{c}}^{\mathrm{T}} \boldsymbol{P}_{\mathrm{c}}+\boldsymbol{P}_{\mathrm{c}} A_{\mathrm{c}}=-\boldsymbol{Q}_{\mathrm{c}} .
$$

Choose the Lyapunov function for the closed loop constituted by Equations (29), (32) and (33) as follows:

$$
V(\boldsymbol{x}, \boldsymbol{z})=\frac{1}{2} \boldsymbol{x}^{\mathrm{T}} \boldsymbol{P}_{\mathrm{c}} \boldsymbol{x}+\left[\frac{8 E^{2} \lambda_{\max }^{2}\left(\boldsymbol{P}_{\mathrm{c}}\right)}{\varepsilon q_{\mathrm{c} 2} q_{\mathrm{o} 2}}\right] V_{\mathrm{o}}(\boldsymbol{z}),
$$


where function $V_{\mathrm{o}}$ is defined by Equation (45). Then, by differentiating function $V$ given by Equation (54) along the closed-loop trajectory, and by considering inequality (46), it can be seen that

$$
\begin{aligned}
\dot{V}_{\mathrm{c}}(\boldsymbol{x}, \boldsymbol{z}) & =-\frac{1}{2}\left[\boldsymbol{x}^{\mathrm{T}} \boldsymbol{Q}_{\mathrm{c}} \boldsymbol{x}+\overline{\boldsymbol{x}}^{\mathrm{T}} \overline{\boldsymbol{R}}_{\mathrm{c}} \overline{\boldsymbol{x}}\right]+\boldsymbol{x}^{\mathrm{T}} \boldsymbol{P}_{\mathrm{c}} \boldsymbol{E}_{\mathrm{d}}+\left[\frac{8 E^{2} \lambda_{\max }^{2}\left(\boldsymbol{P}_{\mathrm{c}}\right)}{\varepsilon^{2} q_{\mathrm{c} 2} q_{\mathrm{o} 2}}\right] \frac{\mathrm{d} V_{\mathrm{o}}(\boldsymbol{z})}{\mathrm{d} \tau} \\
& \leq-\frac{1}{4} \boldsymbol{x}^{\mathrm{T}} \boldsymbol{Q}_{\mathrm{c}} \boldsymbol{x}-\frac{1}{2} \overline{\boldsymbol{x}}^{\mathrm{T}} \overline{\boldsymbol{R}}_{\mathrm{c}} \overline{\boldsymbol{x}}+\frac{E^{2} \lambda_{\max }^{2}\left(\boldsymbol{P}_{\mathrm{c}}\right)}{\varepsilon^{2} q_{\mathrm{c} 2}} z_{2}^{2} \\
& +\left[\frac{8 E^{2} \lambda_{\max }^{2}\left(\boldsymbol{P}_{\mathrm{c}}\right)}{\varepsilon^{2} q_{\mathrm{c} 2} q_{\mathrm{o} 2}}\right]\left[-\frac{1}{2} \overline{\boldsymbol{z}}^{\mathrm{T}} \overline{\boldsymbol{R}}_{\mathrm{o}} \overline{\boldsymbol{z}}-\frac{1}{4} \boldsymbol{z}^{\mathrm{T}} \boldsymbol{Q}_{\mathrm{o}} \boldsymbol{z}+\frac{\varepsilon^{4}}{q_{\mathrm{o} 2}}\left[\frac{D}{E} \lambda_{\max }\left(\boldsymbol{P}_{\mathrm{o}}\right)\right]^{2}\right] \\
& =-\left\{\frac{1}{4} \boldsymbol{x}^{\mathrm{T}} \boldsymbol{Q}_{\mathrm{c}} \boldsymbol{x}+\frac{1}{2} \overline{\boldsymbol{x}}^{\mathrm{T}} \overline{\boldsymbol{R}}_{\mathrm{c}} \overline{\boldsymbol{x}}+\left[\frac{E^{2} \lambda_{\max }^{2}\left(\boldsymbol{P}_{\mathrm{c}}\right)}{\varepsilon^{2} q_{\mathrm{c} 2} q_{\mathrm{o} 2}}\right]\left[4 \overline{\boldsymbol{z}}^{\mathrm{T}} \overline{\boldsymbol{R}}_{\mathrm{o}} \overline{\boldsymbol{z}}+2 q_{\mathrm{o} 1} z_{1}^{2}+q_{\mathrm{o} 2} z_{2}^{2}\right]\right\} \\
& +\frac{8 \varepsilon^{2} D^{2} \lambda_{\max }^{2}\left(\boldsymbol{P}_{\mathrm{c}}\right) \lambda_{\max }^{2}\left(\boldsymbol{P}_{\mathrm{o}}\right)}{q_{\mathrm{c} 2} q_{\mathrm{o} 2}^{2}}
\end{aligned}
$$

where

$$
\bar{x}=P_{\mathrm{C}}^{\frac{1}{2}} x
$$

and

$$
\overline{\boldsymbol{R}}_{\mathrm{C}}=\boldsymbol{P}_{\mathrm{C}}^{\frac{1}{2}} \boldsymbol{R}_{\mathrm{C}} \boldsymbol{P}_{\mathrm{C}}^{-\frac{1}{2}}+\boldsymbol{P}_{\mathrm{C}}^{-\frac{1}{2}} \boldsymbol{R}_{\mathrm{C}} \boldsymbol{P}_{\mathrm{C}}^{\frac{1}{2}}
$$

is a semipostive-definite symmetric matrix represecting the nature dissipation.

From inequality (55), it can be clearly seen that the closed-loop state-vector [x z]T converges the bounded set given by

$$
\Xi=\left\{x, z \in R^{2} \mid \quad x^{\mathrm{T}} Q_{\mathrm{c}} x+2 \bar{x}^{\mathrm{T}} \overline{\boldsymbol{R}}_{\mathrm{c}} \overline{\boldsymbol{x}}+\left[\frac{4 E^{2} \lambda_{\max }^{2}\left(\boldsymbol{P}_{\mathrm{c}}\right)}{\varepsilon^{2} q_{\mathrm{c} 2} q_{\mathrm{o} 2}}\right]\left[4 \overline{\boldsymbol{z}}^{\mathrm{T}} \overline{\boldsymbol{R}}_{\mathrm{o}} \overline{\boldsymbol{z}}+2 q_{\mathrm{o} 1} z_{1}^{2}+q_{\mathrm{o} 2} z_{2}^{2}\right] \leq \frac{32 \varepsilon^{2} D^{2} \lambda_{\max }^{2}\left(\boldsymbol{P}_{\mathrm{c}}\right) \lambda_{\max }^{2}\left(\boldsymbol{P}_{\mathrm{o}}\right)}{q_{\mathrm{c} 2} q_{\mathrm{o} 2}^{2}}\right\}
$$

which shows that the control strategy coupled by ADRC (32) and DO (33) can guarantee the globally bounded closed-loop stability.

Remark 1. From model (29), since

$$
\dot{x}_{1}=x_{2}
$$

and since $x_{2}$ can be directly measured, it can be seen that ADRC (32) can be rewritten as

$$
u=-\frac{E}{b}\left[k_{2} x_{2}+k_{1} \int_{0}^{t} x_{2}(\tau) \mathrm{d} \tau\right]-\frac{\hat{d}}{b}
$$

which is just an addition of feedback action given by a proportional-integral (PI) law and a feedforward action driven by $D O$ (33). In the following section, the influence of feedforward action is studied through simulation.

Remark 2. From Equations (14), (16), (25), and (27), system parameters $E$ and $b$ have no relationship with the type of reactor, which means that ADRC (32) and DO (33) can be applied to AGC of pressurized water reactor (PWR) plants. The corresponding control scheme with AGC function of PWR plants is shown in Figure 4, from which one can see that the difference between the schemes shown in Figures 3 and 4 lies in the TPC part but not in the AGC part. As we know the PC of PWR is in forced circulation and there is no IC in a PWR plant, the difference between the TPC of PWR and that of NHR comes from the circulation type of PC and the existence of IC. 


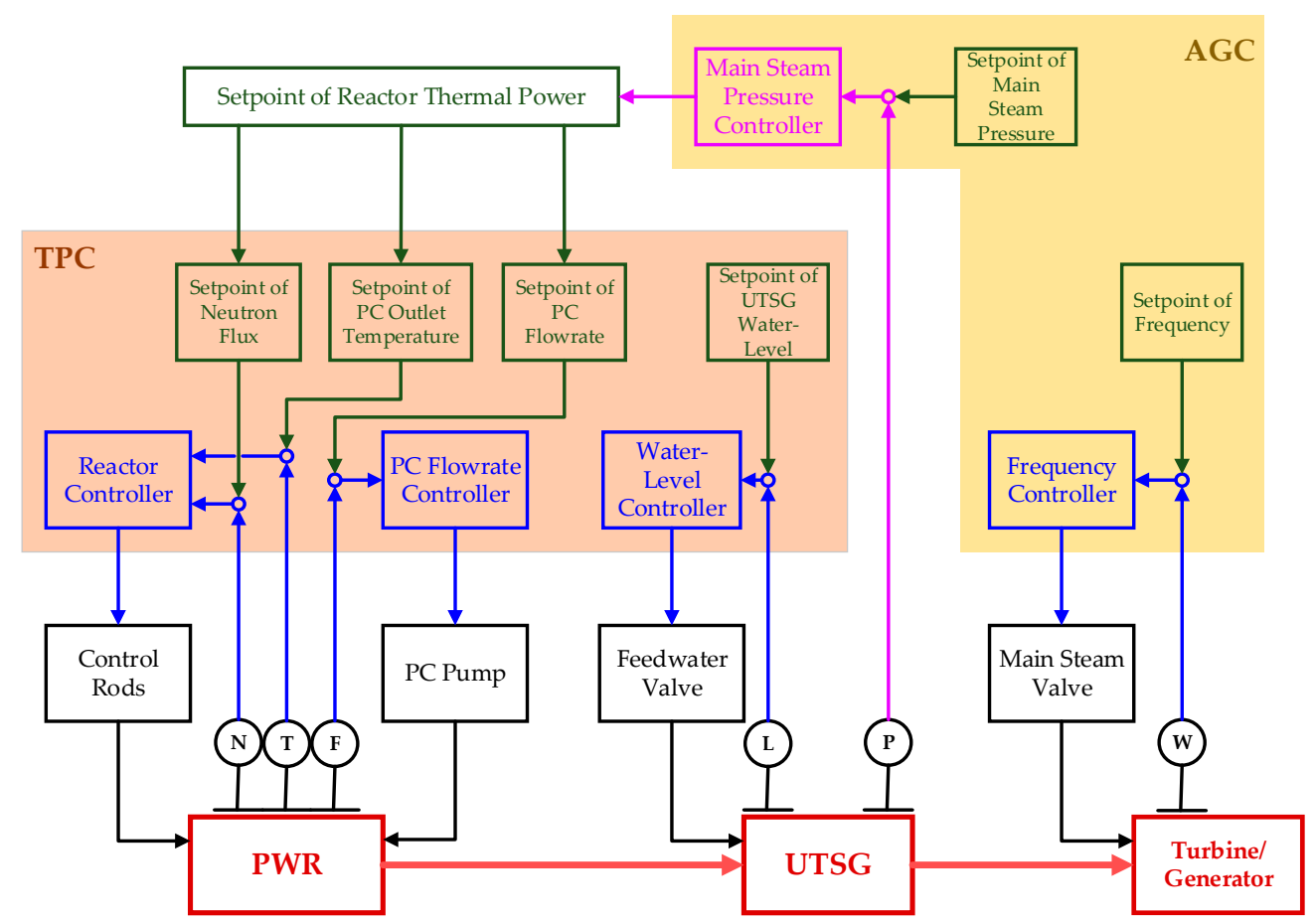

Figure 4. Control scheme diagram of PWR power plant.

\section{Simulation Results with Dissuction}

In this section, ADRC (32) and DO (33) are applied for the AGC of NHR-200II plant. The simulation results in the cases of load stepping and ramping are given.

\subsection{Simulation Program}

Based upon the lumped-parameter dynamic model of NHR200-II reactor and secondary-circuit given in [18], the simulation program is developed in Matlab/Simulink for the verification of the AGC scheme and algorithm. The developed program is shown in Figure 5, where Figure 5a is the entire program, Figure $5 b$ is the NSSS, Figure $5 c$ is the secondary circuit, and Figure $5 d$ is the multimachine power system with three machines and nine nodes. The synchronous generator of NHR plant is connected to the first node in this power grid. The algorithm for solving ordinary differential equations (ODEs) in this numerical simulation software is the variable-step ode23tb with a relative accuracy of $1 \times 10^{-4}$. The control laws in this simulation for regulating the neutron flux, reactor core outlet temperature, and UTSG water level are those presented in $[20,21]$.

\subsection{Simulation Results}

The cases of both load stepping and ramping are considered in this numerical simulation experiment performed based on the program shown in Figure 5, and the corresponding simulation results about the dynamical responses of key process variables are given to show the AGC performance of the NHR-200II power plant. 

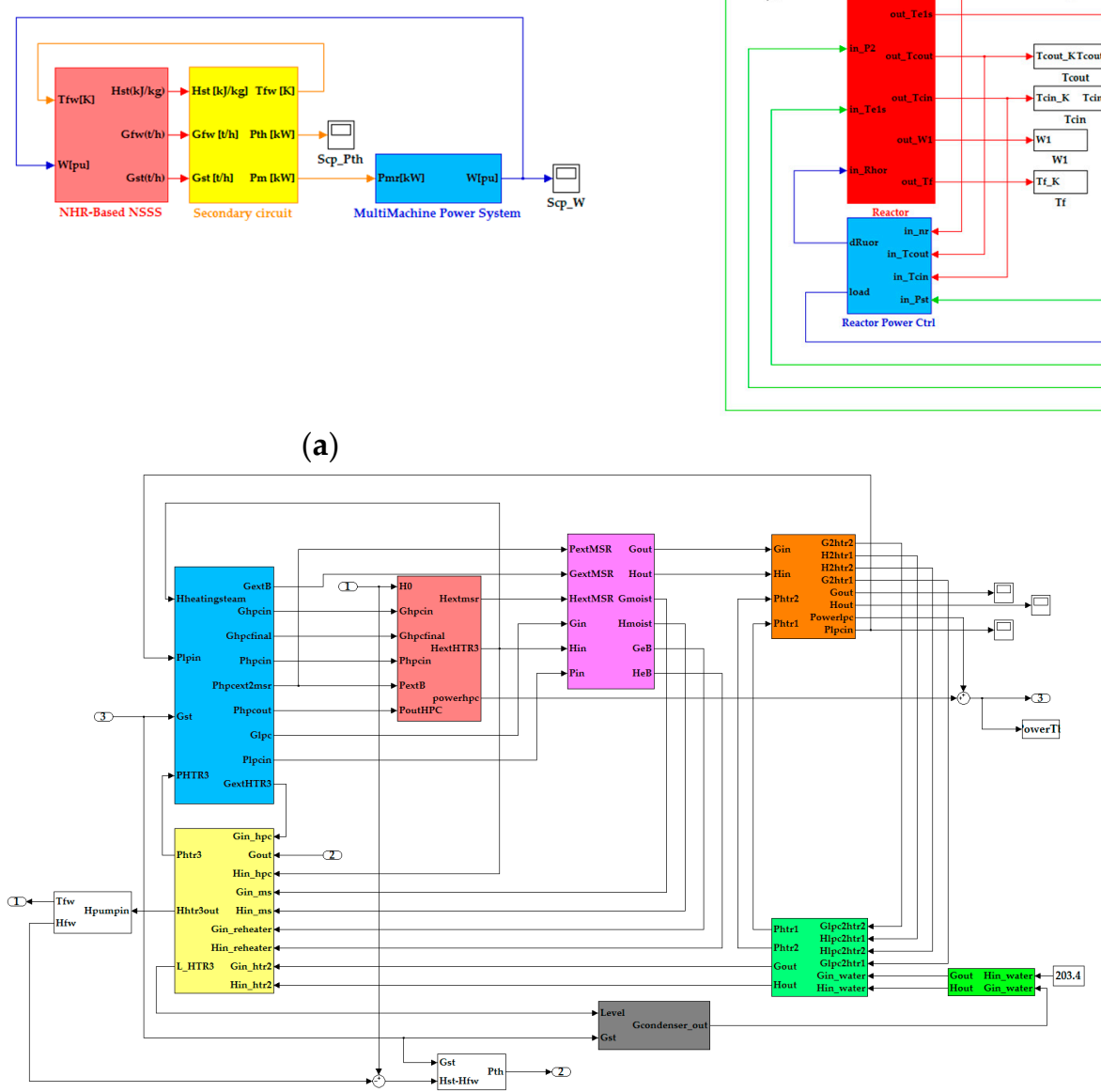

(c)

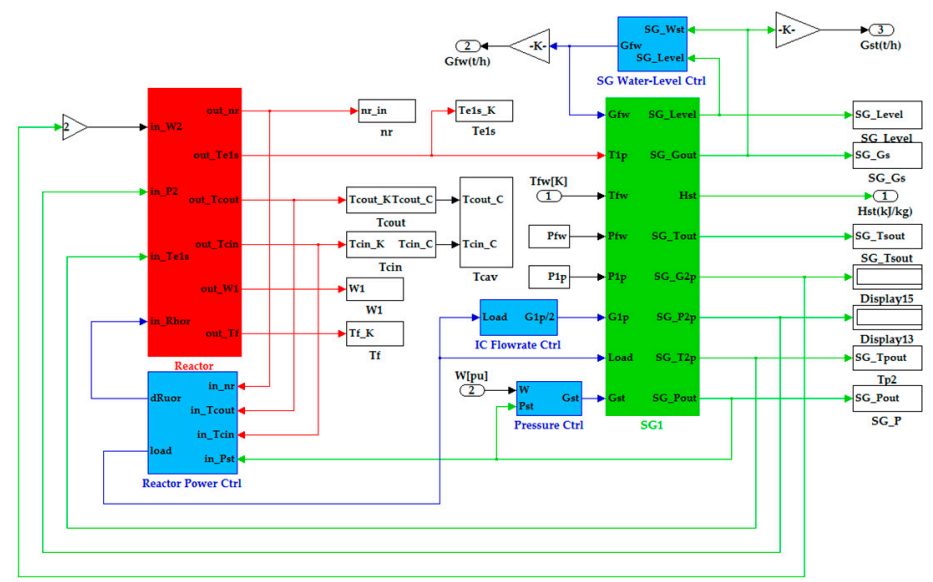

(b)

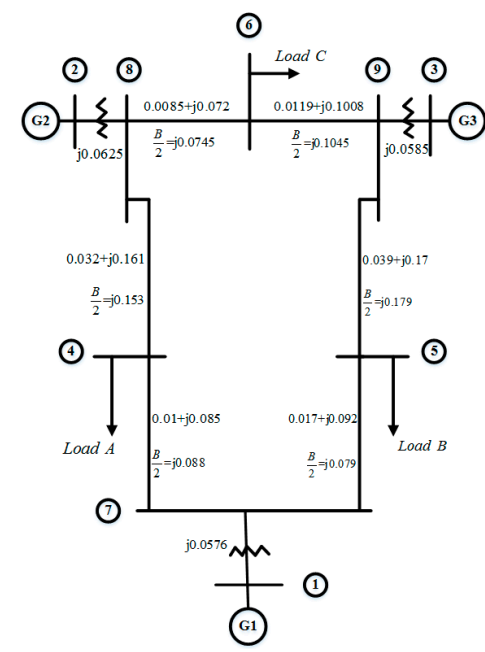

(d)

Figure 5. Simulation program and the corresponding three-machines/nine-nodes power system: (a) whole plant, (b) simulation unit of NSSS, (c) simulation unit of secondary system, (d) power system. 


\section{Load Stepping}

Initially, the NHR-200II plant operates at 100\% plant full power (PFP), and then at $3000 \mathrm{~s}$, load A at node 4 of multimachine power system shown in Figure $5 \mathrm{~d}$ steps down with the amplitude of $5 \mathrm{MW}_{\mathrm{e}}$. The dynamical responses of the plant process variables such as the neutron flux, core outlet temperature, IC hot leg temperature, live steam pressure, UTSG water level and feedwater temperature, thermal power, electric power, normalized grid frequency, and phase angle are shown in Figure 6.
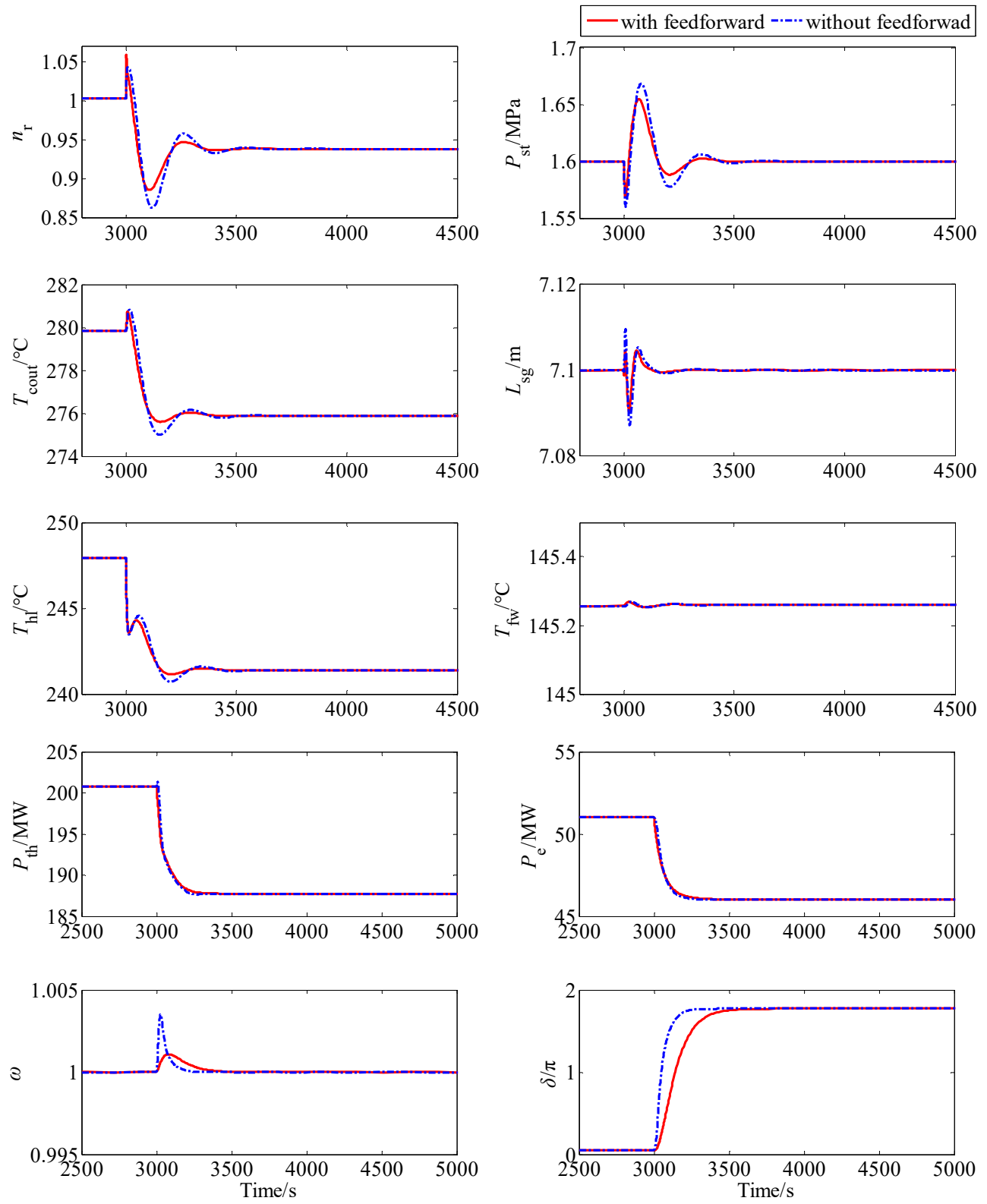

Figure 6. Responses of key process variables in the case of load stepping, $n_{\mathrm{r}}$ : neutron flux, $T_{\text {cout: }}$ : core outlet temperature, $T_{\mathrm{hl}}$ : IC hot leg temperature, $P_{\mathrm{st}}$ : live steam pressure, $L_{\mathrm{sg}}$ : UTSG water-level, $T_{\mathrm{fw}}$ : feedwater temperature, $P_{\mathrm{th}}$ : thermal power, $P_{\mathrm{e}}$ : electric power, $\omega$ : normalized frequency, and $\delta$ : phase angle.

\section{Load Ramping}

The NHR-200II plant also operates at $100 \%$ plant full power (PFP) initially; load A at node 4 ramps down to the level of $10 \mathrm{MW}_{\mathrm{e}}$ lower at $3000 \mathrm{~s}$, and ramps up to its original level at $6000 \mathrm{~s}$, 
where the ramping rate is $5 \mathrm{MW}_{\mathrm{e}} / \mathrm{min}$. The plant dynamical responses of physical, thermal-hydraulic, and electric parameters during load ramping are shown in Figures 7-9.

\subsection{Discussion}

From Figure 6, as the electrical demand drops down, the frequency, i.e., the rotation rate of a synchronous generator increases abruptly, which enlarges the frequency error and further drives the frequency controller to narrow the main steam valve to a smaller opening so as to decrease the frequency. The decrease in the opening of the main steam valve leads to an increase in the live steam pressure, which drives the steam pressure controller to lower the setpoint of thermal power. The variation in referenced thermal power drives the thermal power control system composed of a reactor controller, IC flowrate controller, and UTSG water-level controller to regulate the neutron flux, core outlet temperature, IC flowrates, and water levels so that the actual thermal power can cope with its setpoint. From Figure 6, it can be clearly seen that ADRC (32) can guarantee satisfactory automatic generation performance. Moreover, as we see from Figure 6, the overshoots of steam pressure and frequency corresponding to the control law with feedforward term are much smaller than without. Actually, from Equation (32), the feedforward term is adopted to attenuate the total disturbance estimated by DO (33). If there is no feedforward action, the disturbance can lead to a deviation in process variables, which leads to an increase in variable overshoots. From the first subfigure of Figure 6 , the feedforward term can also result in a slightly larger overshoot of neutron flux. However, due to the inherent safety features of NHR, this overshoot in neutron flux is acceptable.
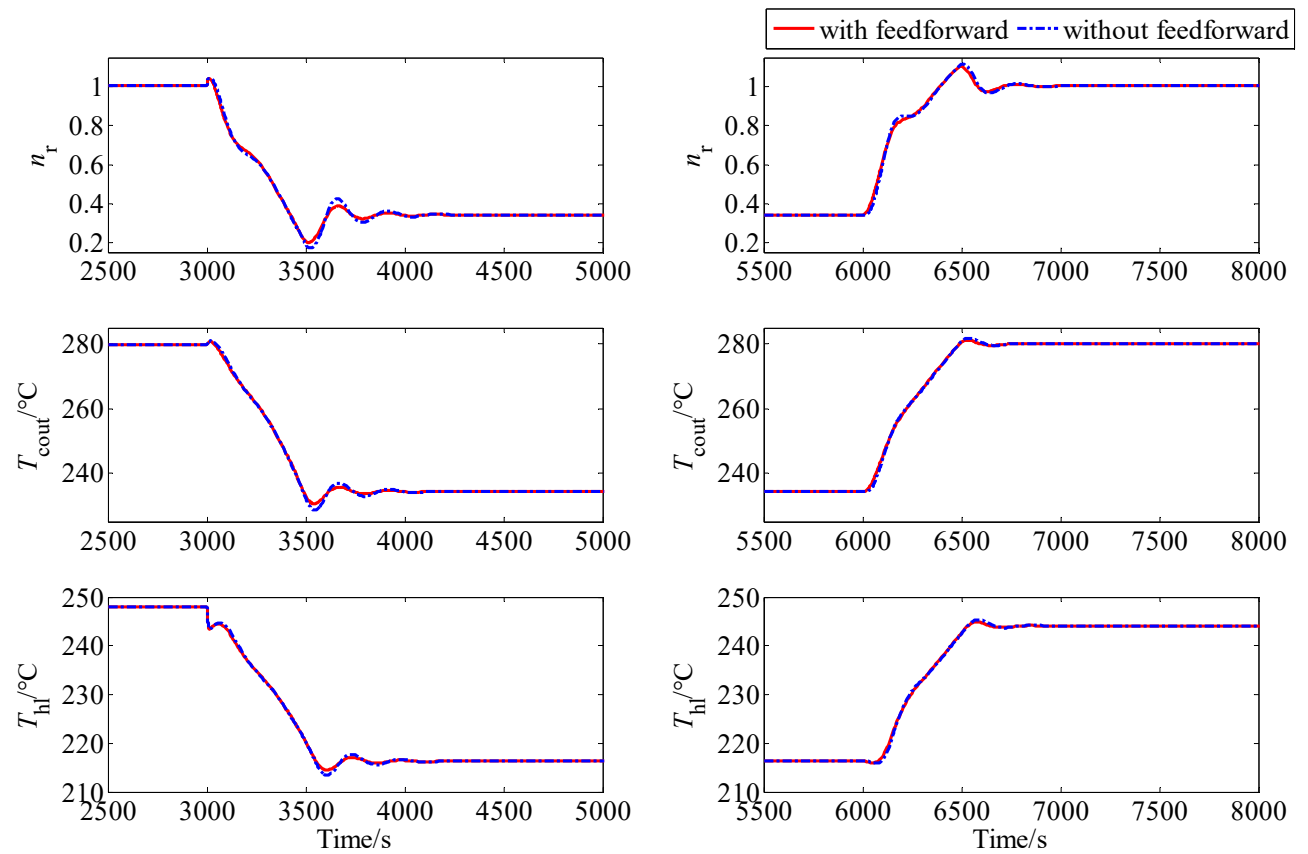

Figure 7. Responses of PC and IC process variables in the case of load maneuvering, $n_{\mathrm{r}}$ : neutron flux, $T_{\text {cout: }}$ core outlet temperature, $T_{\mathrm{hl}}$ : IC hot leg temperature.

Moreover, from Figures 7-9, the ADRC can also provide satisfactory transient in response to the ramping down and up of electrical demand. As we see from Figure 9, the ADRC with feedforward action can provide a slower response of grid frequency than that without. Furthermore, from Figure 8, the feedforward action can lead to smaller overshoot and a smoother response of the main steam pressure. Since the variational rate of the thermal power setpoint in the case of load ramping is much smaller than that in the case of load stepping, the overshoot of neutron flux is much smaller. Then, we can see that the central role of feedforward term is to cancel out the disturbance based on the estimation provided by DO, which can result in the improvement of plant dynamical responses. 
Moreover, since ADRC without feedforward action is just the classical PI control law, it can be seen that the disturbance estimation and attenuation technique is an effective way to improve the control performance for nuclear power plants.
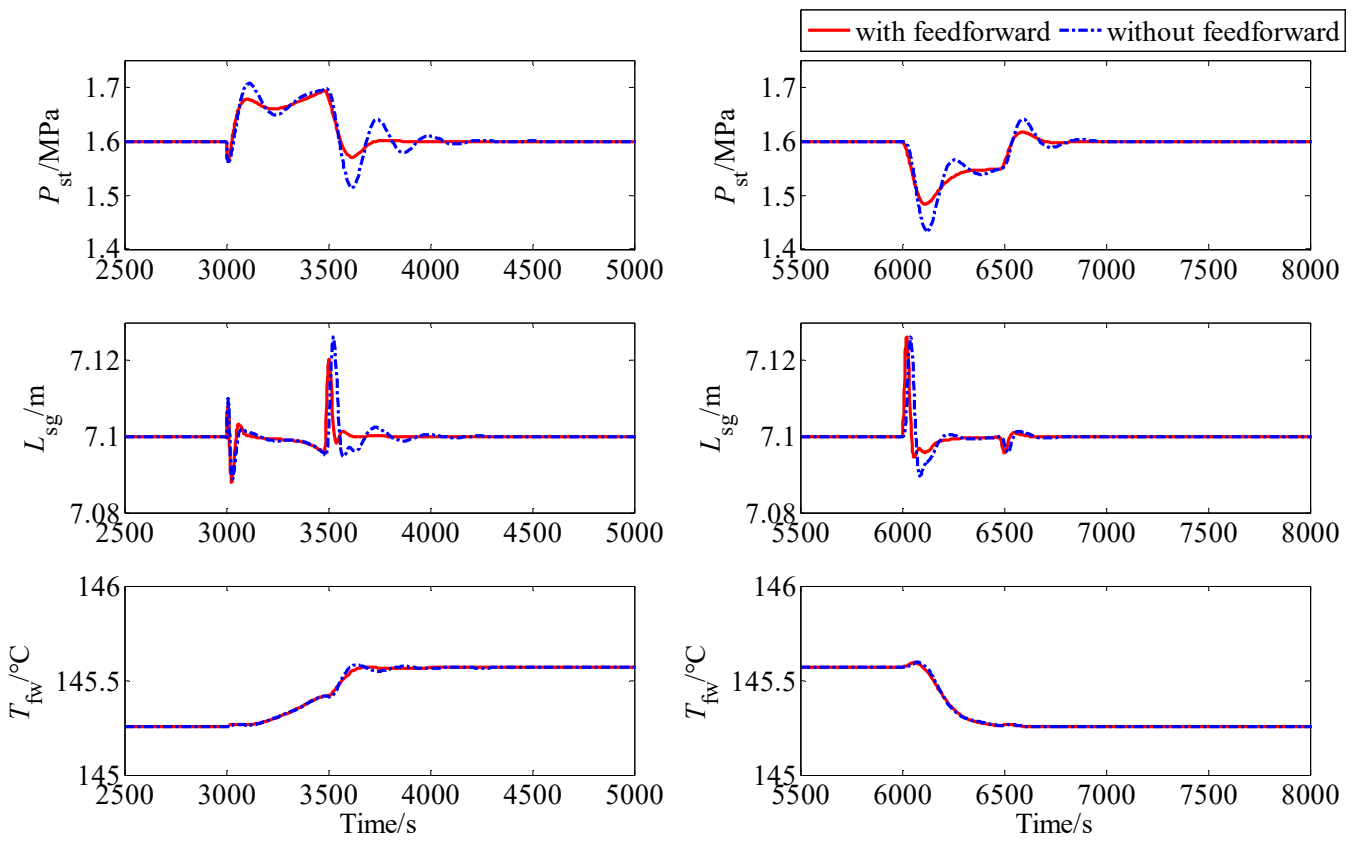

Figure 8. Responses of UTSG process variables in the case of load maneuvering, $P_{\mathrm{st}}$ : live steam pressure, $L_{\mathrm{sg}}$ : UTSG water-level, $T_{\mathrm{fw}}$ : feedwater temperature.
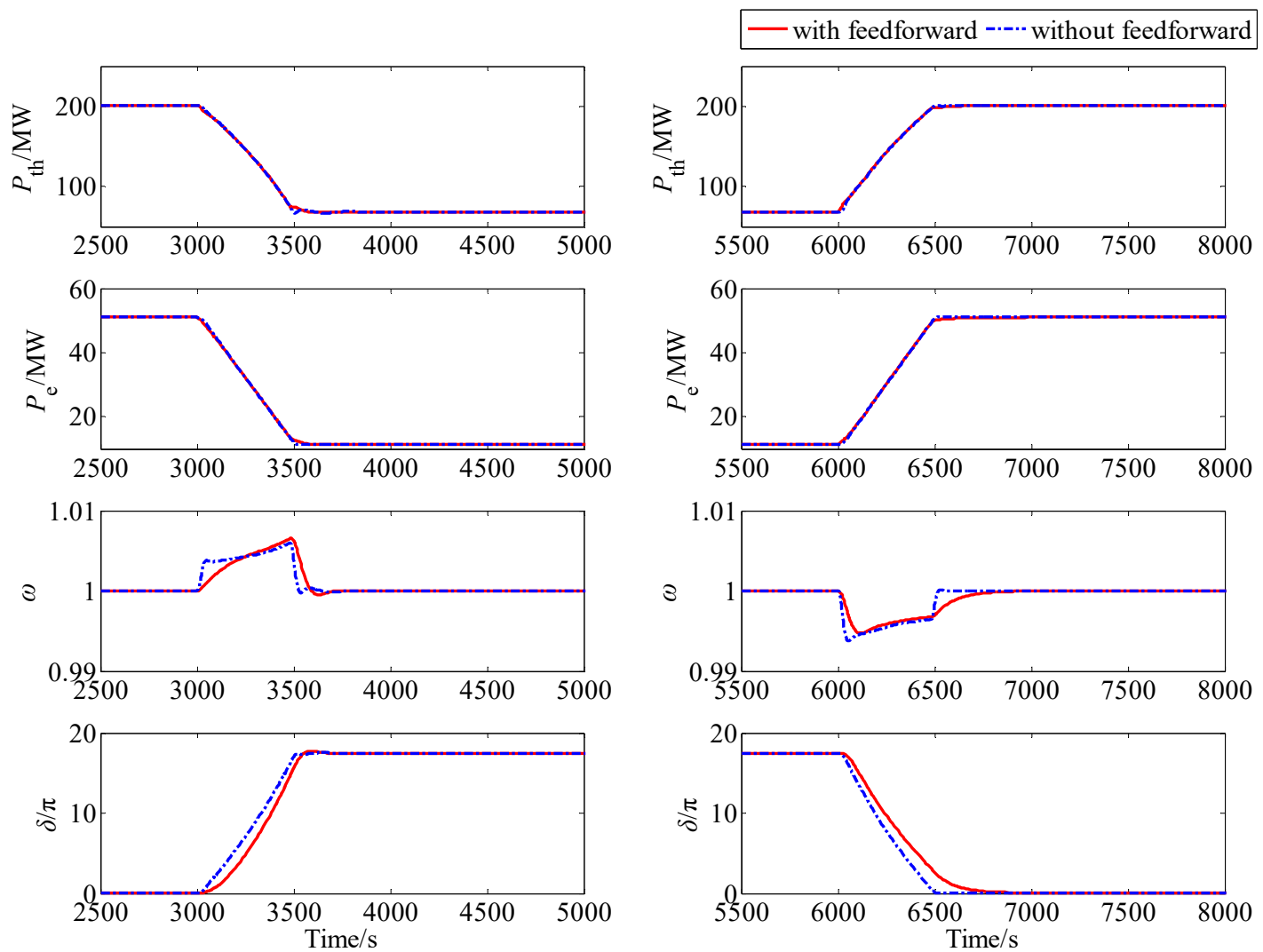

Figure 9. Responses of electric variables in the case of load maneuvering, $P_{\mathrm{th}}$ : thermal power, $P_{\mathrm{e}}$ : electric power, $\omega$ : normalized frequency, and $\delta$ : phase angle. 
Finally, due to the simple expression of ADRC (32) and DO (33), they can be easily implemented on those digital control system platforms. Moreover, the ADRC without a feedforward term, i.e., a PI feedback law, is easier to deploy; however, the trade-off is a deterioration in control performance.

\section{Conclusions}

SMR is one of the main trends in nuclear energy, and iPWR such as Nuscale, SMART, and IRIS are among the most important types. The NHR developed by INET, Tsinghua University is also a typical iPWR with inherent safety features such as self-pressurization, full-power-range natural circulation, and hydraulic control rods. Due to its high level of nuclear safety, it can be adopted to balance the supply and demand of electric power for deepening the penetration of renewable energy resources such wind and solar, which result in the development of NHES. The key feature of NHES is the high flexibility of its NPPs, guaranteed by the AGC function of the plant control system. In this paper, the plant control system of an NHR power plant with AGC function is designed, where the AGC function is realized based on the stabilization of grid frequence and main steam pressure. Then an ADRC law is proposed for realizing the AGC function, which is composed of the feedback control action given by a PI law and the feedforward disturbance attenuation action driven by a well-designed DO. This newly built disturbance attenator is applied to realize the AGC function of the NHR-200II reactor power plant. Simulation results not only show indicate feasibility and satisfactory performance but also illustrate the influence of feedforward disturbance attenuation action on the dynamic responses.

Author Contributions: Conceptualization, Z.D.; Formal analysis, Z.D.; Funding acquisition, Z.D. and X.H.; Methodology, Z.D. and M.L.; Project administration, Y.Z. and Z.Z.; Software Z.D. and M.L.; Validation, D.J. and M.L.

Funding: This research was jointly supported by the Natural Science Foundation of China (NSFC) [Grant No. 61773228] and the National S\&T Major Project of China [Grants No. ZX06902 and ZX06906].

Acknowledgments: The authors would like to thank deeply to the anonymous reviewers for constructive comments on this paper.

Conflicts of Interest: The authors declare no conflict of interest. The founding sponsors had no role in the design of the study; in the collection, analyses, or interpretation of data; in the writing of the manuscript; or in the decision to publish the results.

\section{References}

1. Suman, S. Hybrid nuclear-renewable energy systems: A review. J. Clean. Prod. 2018, 181, 166-177. [CrossRef]

2. Ponciroli, R.; Wang, Y.; Zhou, Z.; Botterud, A.; Jenkins, J.; Vilim, R.B.; Canda, F. Profitability evaluation of load-following nuclear units with physics-induced operation constraints. Nucl. Technol. 2017, 200, 189-207. [CrossRef]

3. Lykidi, M.; Gourdel, P. Optimal management of flexible nuclear power plants in a decarbonizing competitive electricity market: The French case. Energy 2017, 132, 171-185. [CrossRef]

4. Cany, C.; Mansilla, C.; da Mathonnière, C.P. Nuclear power supply: Going against the misconceptions. Evidence of nuclear flexibility from the French experience. Energy 2018, 151, 289-296. [CrossRef]

5. Jenkins, J.D.; Zhou, Z.; Ponciroli, R.; Vilim, R.B.; Ganda, F.; de Sisternes, F.; Botterud, A. The benefits of nuclear flexibility in power system operations with renewable energy. Appl. Energy 2018, 151, 872-884. [CrossRef]

6. Baker, T.E.; Epiney, A.S.; Rabiti, C.; Shittu, E. Optimal sizing of flexible nuclear energy system components considering wind volatility. Appl. Energy 2018, 212, 498-508. [CrossRef]

7. Ingersoll, D.T. Deliberately small reactors and the second nuclear era. Prog. Nucl. Energy 2009, 51, 589-603. [CrossRef]

8. Vujić, J.; Bergmann, R.M.; Škoda, R.; Miletić, M. Small modular reactors: Simpler, safer, cheaper? Energy 2012, 45, 288-295. [CrossRef]

9. Rowinski, M.K.; White, T.J.; Zhao, J. Small and medium sized reactors (SMR): A review of technology. Renew. Sustain. Energy. Rev. 2015, 44, 643-656. [CrossRef] 
10. Ingersoll, D.T.; Houghton, Z.J.; Bromm, R.; Desportes, C. NuScale small modular reactor for co-generation of electricity and water. Desalin 2014, 340, 84-93. [CrossRef]

11. Wang, D.; Ma, C.; Dong, D.; Lin, J. Chinese nuclear heating test reactor and demonstration plant. Nucl. Eng. Des. 1992, 136, 91-98.

12. Wang, D.; Zhang, D.; Dong, D.; Gao, Z.; Li, H.; Lin, J.; Su, Q. Experimental study and operation experiences of the $5 \mathrm{MW}$ nuclear heating reactor. Nucl. Eng. Des. 1993, 143, 9-18.

13. Wang, D. The design characteristics and construction experiences of the $5 \mathrm{MW}$ nuclear heating reactor. Nucl. Eng. Des. 1993, 143, 19-24.

14. Wang, D.; Zheng, W. Technical design features and safety analysis of the $200 \mathrm{MW}$ nuclear heating reactor. Nucl. Eng. Des. 1993, 143, 1-7.

15. Wang, D.; Dong, D.; Zheng, W. The $200 \mathrm{MW}$ nuclear heating reactor and its possible application in seawater desalination. Desalin 1994, 99, 367-381. [CrossRef]

16. Zheng, W.; Wang, D. NHR-200 nuclear energy system and its possible applications. Prog. Nucl. Energy 1995, 29, 193-200.

17. Li, W.; Zhang, Y.; Zheng, W. Investigation on three seawater desalination processes coupled with NHR-200. Desalin 2012, 298, 93-98. [CrossRef]

18. Dong, Z.; Pan, Y. A lumped-parameter dynamical model of a nuclear heating reactor cogeneration plant. Energy 2018, 145, 638-656. [CrossRef]

19. Li, G.; Wang, X.; Liang, B.; Li, X.; Zhang, B.; Zou, Y. Modeling and control of nuclear reactor cores for electricity generation: A review of advanced technology. Renew. Sustain. Energy Rev. 2016, 60, 116-128. [CrossRef]

20. Dong, Z. PD power-level control design for PWRs: A physically-based approach. IEEE Trans. Nucl. Sci. 2013, 60, 3889-3898. [CrossRef]

21. Dong, Z.; Huang, X.; Feng, J. Water-level control for the U-tube steam generator of nuclear power plants based on output feedback dissipation. IEEE Trans. Nucl. Sci. 2009, 56, 1600-1612. [CrossRef]

(C) 2018 by the authors. Licensee MDPI, Basel, Switzerland. This article is an open access article distributed under the terms and conditions of the Creative Commons Attribution (CC BY) license (http:/ / creativecommons.org/licenses/by/4.0/). 